\title{
An Update on Medical Treatment Options for Hidradenitis Suppurativa
}

\author{
I. E. Deckers ${ }^{1}$ - E. P. Prens ${ }^{1}$
}

Published online: 11 December 2015

(c) Springer International Publishing Switzerland 2015

\begin{abstract}
Hidradenitis suppurativa (HS) is a chronic inflammatory skin disease characterized by recurrent inflammatory nodules mostly located in the armpits and groin. Over the years multiple treatments for HS have been proposed; however, to date a cure is still lacking. In this update we provide an overview of most drug treatments reported on for HS, where possible with their mode of action and side effects. In mild cases, clindamycin lotion or resorcinol cream have proven effective. Tetracyclines are a first-line systemic option in more widespread or severe cases, followed by the combination of clindamycin and rifampicin. However, the recurrence rate is high after discontinuation of clindamycin plus rifampicin combination therapy. Long-term treatment with retinoids, especially acitretin is feasible, although teratogenicity has to be taken into account in females of reproductive age. Multiple antiinflammatory drugs have been suggested for HS, such as dapsone, fumarates or cyclosporine. However, their effectiveness in HS is based on small case series with varying results. If most common treatments have failed, biologics (e.g., infliximab or adalimumab) are the next step. Although not addressed in this review, surgical interventions are often needed to achieve remission.
\end{abstract}

E. P. Prens

e.prens@erasmusmc.nl

I. E. Deckers

i.deckers@erasmusmc.nl

1 Department of Dermatology, Erasmus University Medical Center, Burg. s' Jacobplein 51, 3015 CA Rotterdam, The Netherlands

\section{Key Points}

Hidradenitis suppurativa (HS) is a chronic inflammatory skin disease without a cure.

Antibiotics (topical or oral) are often the first treatment option for HS.

In cases of more extensive or therapy-resistant HS, biologicals (e.g., infliximab or adalimumab) are a good therapeutic option.

\section{Introduction}

Hidradenitis suppurativa (HS), also known as acne inversa, is a chronic, recurrent inflammatory skin disease $[1,2]$. The diagnosis is based on the clinical presentation. Patients present with comedones, inflamed or non-inflamed nodules, and abscesses, often followed by sinus tract formation, and scarring. These lesions are generally present in the axillary, inguinal, pubic, and gluteal area, and the inframammary area in female patients. To make the diagnosis, these painful or purulent nodules have to occur at least twice in six months [3]. The disease usually develops after puberty, when patients are in their early twenties. However, although rare, HS can also develop in children $[4,5]$. The disease has a prevalence ranging from 0.05 to $4 \%$, and females are more often affected than males, with a female to male ratio of 3:1 [6-8]. Disease severity can be assessed using different severity scores. The oldest and still most commonly used severity assessment is the Hurley score (Table 1; Fig. 1) [2,9]. It is easy to use, but static and 
therefore less suitable for monitoring treatment efficacy. The modified Sartorius score is more dynamic. It is based on the number of areas involved and the number of nodules, fistulas, and hypertrophic scars $[10,11]$. However, because of its comprehensiveness, it is time consuming, making it less suitable for daily practice. The hidradenitis suppurativa physician global assessment (HS-PGA) score is suitable for observing change during treatment and is easy to use and validated [3, 12], therefore it is frequently used at present (Table 2).

The pathogenesis of HS is still not fully understood. The primary event is thought to be infundibular hyperkeratosis and hyperplasia of the follicular epithelium causing occlusion of hair follicles [13, 14]. This leads to accumulation of cellular debris and cyst formation, and eventually rupture of the hair follicle causing abscess formation and the development of sinus tracts and scarring $[15,16]$. The role of an aberrant immune response gets more attention in the pathogenesis of HS. Elevated levels of interleukin (IL)$1 \beta$, IL-10, and tumor necrosis factor alpha (TNF- $\alpha$ ) have been found in lesional and perilesional skin [17]. Also overexpression of macrophages producing IL-12 and IL23, and IL-17-producing cells were found in lesional HS skin [18]. These results were recently confirmed by Kelly et al. [19]. They also demonstrated activated caspase- 1 in HS skin, which is associated with IL-1 $\beta$ and IL-18 production. These results suggest that the IL-23/Th17 and the caspase-1 pathways play an important role in the pathogenesis of HS [17-19].
To date, there is no medical cure for HS, and multiple treatments have been suggested for HS. Often a combination of drug treatment and surgical intervention is needed to achieve remission. Recently the European Guidelines for the treatment of HS have been published [3], giving advice on the therapeutic steps to be taken in the treatment of HS. In this comprehensive review we will give an overview of most HS drug treatments with their mode of action. The commonly used antibiotics and biologics will be discussed, as will a few more experimental and future therapeutic options.

\section{Topical Treatments}

For mild HS, where only comedones, papules, pustules, or inflammatory nodules are present, topical treatment, together with lifestyle advice, are often sufficient. The best results are achieved when a combination of a peeling cream, to resolve and prevent follicular blockage, is given with a local antibiotic, as a topical anti-inflammatory agent and to prevent secondary infection.

\subsection{Topical Clindamycin}

Topical clindamycin is a simple and widely used treatment for HS [20]. Daily topical application of clindamycin $1 \%$ proved more effective than placebo in a small double-blind study of patients with Hurley stage I and mild stage II HS.

Table 1 Hurley's classification for clinical staging of disease severity in hidradenitis suppurativa [2, 9]

\begin{tabular}{ll}
\hline Stage & Description \\
\hline I & Abscess formation, single or multiple, without sinus tracts and cicatrization \\
II & Recurrent abscesses with tract formation and cicatrization. Single or multiple separated lesions \\
III & Multiple interconnected tracts and abscesses throughout an entire anatomic area \\
\hline
\end{tabular}

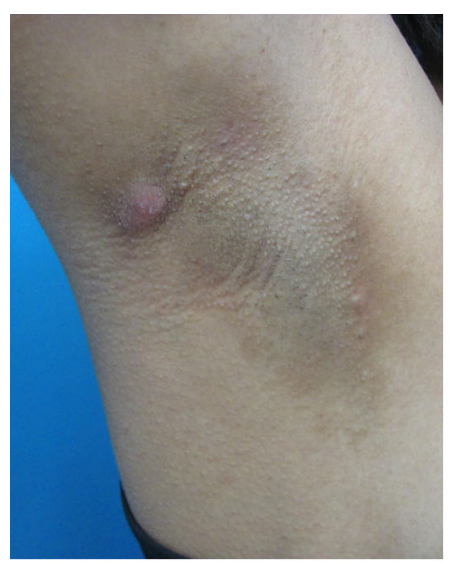

Hurley stage I

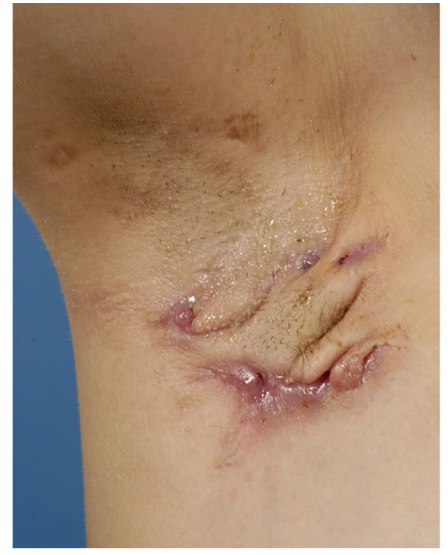

Hurley stage II

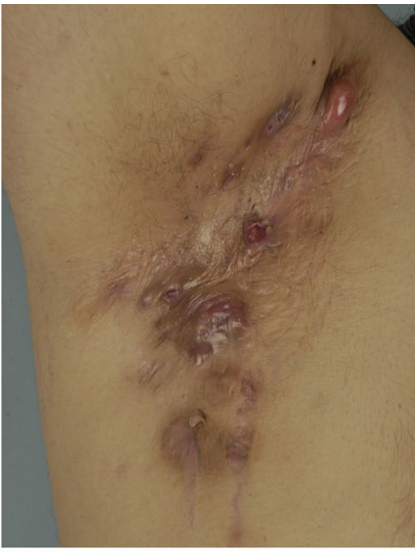

Hurley stage III

Fig. 1 Clinical presentation of the three stages of disease severity of hidradenitis suppurativa according to Hurley $[2,9]$ 
Table 2 Physician's global assessment scale of hidradenitis suppurativa ${ }^{a}$

\begin{tabular}{ll}
\hline Clear & No inflammatory or non-inflammatory nodules \\
Minimal & Only non-inflammatory nodules \\
Mild & Less than five inflammatory nodules; or only one abscess or draining fistula present \\
Moderate & Five or more inflammatory nodules; or one abscess or draining fistula and at least one inflammatory nodule; or \\
& two to five abscesses or draining fistulas an less than ten inflammatory nodules \\
Severe & Two to five abscesses or draining fistulas and ten or more inflammatory nodules \\
Very severe & More than five abscesses or draining fistulas \\
\hline
\end{tabular}

a Adjusted physician's global assessment scale for hidradenitis suppurativa [3, 12]

After 3 months of clindamycin application a significant reduction in pustules, inflammatory nodules, and abscesses was observed. The only side effect was a slight burning sensation after application [21]. For solitary nodules, clindamycin is an effective, safe, and low-cost option.

\subsection{Resorcinol Cream}

In our center resorcinol cream is commonly used. It has a peeling effect on the skin, due to its keratolytic properties at higher concentrations. It is hypothesized that it targets the follicular keratin plug, which is considered be a primary event in the pathogenesis of HS [13, 14, 22]. In addition, it also has an antiseptic effect. The effectiveness of resorcinol 10-15\% has been described in a small study of 12 patients. After daily application, patients reported a decrease in pain and a reduction in the number of days the nodules and abscesses persisted [23]. In our clinical experience, resorcinol effectively prevents new inflammatory lesions by reducing follicular occlusion and it also helps to resolve active nodules faster. However, patients should be warned that resorcinol should be applied to limited skin areas to prevent systemic exposure due to absorption, and that it can have a discoloring effect on their skin and cloths. In addition, due to insufficient data, the use of resorcinol should be avoided during pregnancy [22, 23].

\subsection{Other Topical Agents}

Topical antiseptics, such as iodine scrubs or chlorhexidine, are widely used for HS [20]. They can be effective by preventing secondary bacterial infection of lesions. However, their efficacy in HS has never properly been investigated.

Azelaic acid is registered for mild acne. In vitro it has been shown to have antifungal and bacteriostatic properties, and to inhibit keratinocyte proliferation [22, 24]. It is suggested that azelaic acid can have preventive properties in HS; however, this is based on clinical experience and no studies are available on its use in HS [22]. Nothing is known about the efficacy or usefulness in HS of topical agents such as salicylic acid, tretinoin, adapalene, and benzoyl peroxide, which form the basis of treatment for acne vulgaris.

\section{Systemic Antibiotics}

Even though bacterial infections are not primarily involved in the early phase of the pathogenesis of HS, antibiotics are the treatment of first choice [3]. Cultures of HS lesions are often sterile or show common skin flora [3, 25, 26]. Most commonly found bacteria are coagulase-negative staphylococci (CoNS), Staphylococcus aureus, and strains of the intestinal flora such as Proteus mirabilis, Enterococcus faecalis, or Escherichia coli [26-31]. S. aureus is mostly cultured from chronic suppurative lesions, suggesting that it is not pathogenic in HS, but mostly a superinfection of already existing lesions [27, 30]. CoNS are more often found in deep lesions. In addition, it has recently been shown that Staphylococcus lugdunesis was often found in Hurley stage I lesions, whereas in Hurley stage II or III more often a mixed group of anaerobic flora can be found, including strict anaerobes, anaerobic actinomycetes, and streptococci of the milleri group [32]. However, antibiotics are also thought to be effective because of their anti-inflammatory properties, and in addition by treating or preventing superinfections. In mild cases long-term antibiotics can lead to total remission (Table 3). However, when fistulas, scars, or fibrosis are present, antibiotics are rarely curative, but they can reduce the amount of inflammation and improve conditions for surgery.

\subsection{Tetracyclines}

Antibiotics from the tetracycline group are the first-line systemic treatment for HS [20, 29, 33]. Tetracyclines are broad-spectrum antibiotics and act by inhibition of bacterial protein synthesis through reversible binding to the $30 \mathrm{~S}$ ribosomal subunit [34]. In addition, tetracyclines have multiple non-antibiotic properties. They act in an anti-inflammatory fashion by suppressing chemotaxis and 
Table 3 An overview of articles published on systemic antibiotics for hidradenitis suppurativa

\begin{tabular}{|c|c|c|c|}
\hline & $n^{\mathrm{a}}$ & Dose and duration & Outcome \\
\hline \multicolumn{4}{|l|}{ Tetracyclines } \\
\hline Jemec and Wendelboe [37] & 24 & Tetracycline $500 \mathrm{mg}$ bd, 3 months & $\begin{array}{l}\text { Reduction in physician's and patient's overall } \\
\text { evaluation, soreness, and abscesses. No data on } \\
\text { number of responders. No difference in results } \\
\text { compared with clindamycin } 1 \% \text { lotion }\end{array}$ \\
\hline \multicolumn{4}{|l|}{ Clindamycin and rifampicin } \\
\hline Mendonça and Griffiths [46] & 14 & $\begin{array}{l}\text { Clindamycin } 300 \mathrm{mg} \text { bd, rifampicin } 300 \mathrm{mg} \text { bd, } \\
10 \text { weeks }\end{array}$ & $\begin{array}{l}\text { Eight showed complete remission, two switched } \\
\text { from clindamycin to minocycline, and four } \\
\text { stopped because of side effects }\end{array}$ \\
\hline Gener et al. [47] & $70^{\mathrm{b}}$ & $\begin{array}{l}\text { Clindamycin } 300 \mathrm{mg} \text { bd, rifampicin } 600 \mathrm{~g} \mathrm{qd} \text {, } \\
10 \text { weeks }\end{array}$ & $\begin{array}{l}\text { Eight showed complete response, } 51 \text { partial } \\
\text { response, and three no response or worsening. } \\
\text { Eight stopped because of side effects }\end{array}$ \\
\hline Van der Zee et al. [48] & 34 & Different dose schemes and treatment durations & $\begin{array}{l}\text { Sixteen showed complete remission, } 12 \text { partial } \\
\text { remission, and no response in six patients }\end{array}$ \\
\hline Bettoli et al. [49] & 23 & $\begin{array}{l}\text { Clindamycin } 600 \mathrm{mg} \mathrm{qd} \text {, rifampicin } 600 \mathrm{mg} \mathrm{qd} \text {, } \\
10 \text { weeks }\end{array}$ & $\begin{array}{l}\text { Seventeen showed response (reduction of } 25 \% \text { in } \\
\text { Sartorius score). No response in three patients. } \\
\text { Three stopped because of side effects or personal } \\
\text { reasons }\end{array}$ \\
\hline \multicolumn{4}{|c|}{ Rifampicin, moxifloxacin, and metronidazole } \\
\hline Join-Lambert et al. [54] & 28 & $\begin{array}{l}\text { Rifampicin } 10 \mathrm{mg} / \mathrm{kg} \mathrm{qd} \text {, moxifloxacin } 400 \mathrm{mg} \mathrm{qd} \text {, } \\
\text { metronidazole } 500 \mathrm{mg} \text { tid, minimum } 6 \text { weeks }\end{array}$ & $\begin{array}{l}\text { Sixteen showed complete remission, and } 12 \text { partial } \\
\text { remission }\end{array}$ \\
\hline
\end{tabular}

neutrophil migration, inhibiting the expression of nitric oxide synthase, downregulating pro-inflammatory cytokines such as TNF- $\alpha$ and IL- $1 \beta$, and upregulating the antiinflammatory cytokine IL-10 [34-36]. Furthermore, they can inhibit angiogenesis [35], which is a common process in HS inflammation.

Because of these anti-inflammatory properties and a mild side-effect profile, tetracyclines are useful for longterm treatment and stabilization of HS [29, 33]. However, they are less effective in treating or preventing exacerbations of HS. Matusiak et al. [29] cultured the bacteria isolated from HS patients and found that $64 \%$ of the isolated strains were resistant for tetracyclines. In addition, in a randomized double-blind controlled trial, topical clindamycin $1 \%$ lotion was shown to be as effective as systemic tetracycline $500 \mathrm{mg}$ twice daily in terms of number of nodules and abscesses and patient pain score [37]. Although no studies are available on the effectiveness of doxycycline or minocycline in HS, we believe that they can be very effective in mild HS when given for several months.

Common side effects of tetracyclines are photosensitivity, gastrointestinal complaints, and irreversible dental staining in children $[36,38]$. Tetracyclines should not be taken together with iron supplements, antacids, or milk, because together they can form insoluble complexes in the intestine, and reduce their absorption. In addition, the use of tetracyclines during pregnancy is contraindicated because of the risk of intrauterine dental staining and hepatic necrosis in pregnant women [39].

\subsection{Clindamycin and Rifampicin Combination Therapy}

Most studies on antibiotics in HS have been published on the combination therapy of clindamycin and rifampicin. Clindamycin is produced by substituting chlorine to the hydroxyl group of lincomycin, an antibiotic isolated from a strain of Streptomyces lincolnesis in the early 1960s [40]. Clindamycin is a broad-spectrum antibiotic, and is effective against Gram-positive bacteria and strains of Staphylococcus aureus, with the exception of Streptococcus faecalis. However, most aerobic Gram-negative bacteria are resistant to clindamycin [40]. Clindamycin binds to the 50S ribosomal subunit leading to inhibition of the bacterial protein synthesis. Besides its bacteriostatic effects, clindamycin has marked immune-enhancing properties. It enhances chemotaxis and phagocytosis, and increases TNF and IL-6 release [41, 42].

Rifampicin is a chemically modified version of rifamycin, a natural metabolite of Nocardia mediterranei, and is active against Gram-positive cocci (including Staphylococcus aureus), Gram-negative cocci and bacilli, and most anaerobes. Its bactericidal action is by inhibition of bacterial DNA-dependent RNA polymerase, and is effective at extremely low concentrations and penetrates well into 
many body tissues [43]. Rifampicin also has mild immunosuppressive properties, which is not unexpected since it is structurally related to the clear immunosuppressive macrolides such as tacrolimus and rapamycin. It suppresses T-cell function and in vitro it was shown to reduce lymphocyte transformation [44]. In vitro, rifampicin has also been shown to inhibit IL- $1 \beta$ and TNF- $\alpha$ secretion, whereas IL-6 and IL-10 secretion was significantly increased in rifampicin-treated mononuclear cells [45].

For HS the most common regimen is clindamycin $300 \mathrm{mg}$ twice daily, and rifampicin $600 \mathrm{mg}$ once daily or $300 \mathrm{mg}$ twice daily, for a period of 10 weeks. To date, four studies have been published in which a total of 187 patients were treated [46-49]. However, since in these studies different doses and different outcome variables were used to assess efficacy (Table 3), it is difficult to compare or group these studies. In three retrospective studies, 164 patients were treated of whom 88 patients completed a 10-week course of clindamycin $300 \mathrm{mg}$ twice daily, and rifampicin $600 \mathrm{mg}$ once daily or $300 \mathrm{mg}$ twice daily [46-48]. Twentyone patients could not complete the treatment period because of side effects, mostly diarrhea and nausea. No data were available for the 55 patients regarding the efficacy after 10 weeks, or different dosage regimens were used. Of the 88 patients, 25 had a complete remission $(28.4 \%)$ and another 57 showed a partial response $(64.8 \%)$. In only six patients was the treatment either not effective or worsening was observed $(6.8 \%)$. However, relapse rates of up to $61.5 \%$ have been reported after discontinuation of the therapy [46-48]. In the only prospective study available to date, 20 of 23 patients completed the 10-week treatment course, and of these 17 had a reduction of $25 \%$ in the Sartorius score. One patient stopped prematurely because of gastrointestinal side effects [49].

It has been suggested that clindamycin and rifampicin have a synergistic bactericidal effect on $S$. aureus in vivo [50]. Some studies have shown that the serum concentration of clindamycin is dramatically reduced, up to even $82 \%$ of the peak concentration, when given together with rifampicin [51-53]. Rifampicin is a potent inducer of cytochrome p450, whereas clindamycin is metabolized through a member of the cytochrome P450 system, namely CYP3A4. This might explain the low serum levels of clindamycin. In addition, when both are taken orally, rifampicin may reduce the hepatic first-pass effect of clindamycin, further reducing the bioavailability of clindamycin [51].

Most common side effects of clindamycin as well as of rifampicin are gastrointestinal complaints, such as nausea, vomiting, and diarrhea [40, 44]. In addition rifampicin can cause a red/orange discoloration to urine, sputum, and tears, and can permanently discolor soft contact lenses
[44]. Clindamycin is considered relatively safe for use during pregnancy, since it is unlikely that children of women treated with clindamycin during pregnancy have a high risk of congenital anomalies [39]. However, for rifampicin insufficient data are available on use during pregnancy and therefore its use in these situations should be avoided [39]. Because rifampicin interferes with the metabolism of oral contraceptives, female patients should use extra birth control measures [44].

\subsection{Rifampicin, Moxifloxacin, and Metronidazole Triple Therapy}

For severe or therapy-resistant patients, the combination of rifampicin, moxifloxacin, and metronidazole is an alternative therapeutic option [54]. Metronidazole was originally intended as an antiprotozoal agent that later proved very effective for Gram-negative anaerobic bacteria. In the presence of bacteria, it forms a redox intermediate metabolite causing DNA strand breakage, repair inhibition, and ultimately disrupted transcription and cell death [55]. In addition, it has immunosuppressive properties. Metronidazole can decrease the levels of IL-1 $\beta$, IL-6, IL-8, IL-12, interferon (INF)- $\gamma$, and TNF- $\alpha$. It also has anti-inflammatory effects by blocking the migration of leukocytes from blood into the tissues [56]. Moxifloxacin is an extendedspectrum fluoroquinolone that inhibits bacterial DNA topoisomerases, influencing the replication, transcription, repair, and recombination of the bacterial DNA [57]. Moxifloxacin is a broad-spectrum antibiotic, and is effective against Gram-positive, Gram-negative, and atypical respiratory pathogens. It also has been shown to be effective against $S$. aureus and $S$. pyogenes. Furthermore, Moxifloxacin has immunomodulatory properties; it inhibits the secretion of IL- $1 \alpha$ and TNF- $\alpha$ by monocytes [58]. Moxifloxacin is not metabolized by cytochrome $\mathrm{P} 450$, therefore its availability is not affected when taken together with rifampicin.

In a retrospective study by Lamber et al. [54], $28 \mathrm{HS}$ patients were treated with a combination of rifampicin (10 mg/kg once daily), moxifloxacin (400 mg daily), and metronidazole (500 $\mathrm{mg}$ three times daily). Sixteen patients in this study showed complete remission and another 12 patients showed a partial response [54]. To avoid neurological complaints, the metronidazole was stopped after 6 weeks, but reintroduced in four patients because of recurrence. Over the past few years we have treated multiple HS patients with the above "triple therapy" with good results as long as the patients are taking the drugs.

The most common side effects of metronidazole are nausea, headache, and a metallic taste. A serious but rare adverse effect of metronidazole is central or peripheral nervous system toxicity. In a recent review, Cação et al. [59] 
reported on 84 cases of metronidazole-induced neurotoxicity. In most cases $(90.5 \%)$ the central nervous system (CNS) was involved, mostly causing cerebellar ataxia, encephalopathy, or seizures. In addition, polyneuropathy was reported in 26 cases. After discontinuation of metronidazole, the CNS toxicity resolved in $92 \%$, whereas $37 \%$ of the patients with polyneuropathy had complete resolution [59]. Patients with longer treatment duration or higher doses do not seem to be at a higher risk of developing CNS toxicity [60]. It is important to inform patients to stop or minimize alcohol intake during treatment with metronidazole since this can lead to disulfiram-like reactions [55]. Most frequent side effects of moxifloxacin are nausea, diarrhea, and dizziness. In addition, it can cause $\mathrm{QT}_{\mathrm{c}}$-interval prolongation, therefore combination with class IA or class III antiarrhythmic drugs should be avoided [57]. The bioavailability of moxifloxacin is substantially reduced when taken together with antacids, sucralfate, or iron preparations.

All three antibiotics are contraindicated during pregnancy or breast-feeding. Female patients should use extra contraceptive measures because of the interaction of rifampicin with oral contraceptives.

\section{Biologics}

Since the early 2000s biologics are an upcoming treatment for HS. The efficacy of infliximab, a TNF- $\alpha$ inhibitor, was first described in HS patients with concomitant Crohn's disease (CD) [61, 62]. The first case was a 30-year-old female CD patient who developed perianal abscesses, later followed by inflammatory nodules in both axillae. Antibiotic therapies had only a temporary effect. After one dose of infliximab all her lesions significantly improved, and after the second dose the patient stayed in remission for up to 6 months [61]. Shortly after, Katsanos et al. [62] reported on a 39-year-old male CD patient who presented with bilateral fistulizing axillary HS. He was started on infliximab and after 1 year all of his fistulas dried up and closed. In the following years, multiple case studies followed on the use of TNF- $\alpha$ inhibitors in HS. Other biologics were also given, such as adalimumab, etanercept, and anakinra. Recently the results of the first large randomized controlled multicenter trial on the use of adalimumab in HS patients has been published [12]. Even though biologics are seldom curative in HS, they can suppress the symptoms and can often be given for a prolonged period, making them a good treatment option for chronic HS. The negative aspects of biologics are the cost and that reimbursement is not covered by all insurance companies [63].

Overall, anti-TNF- $\alpha$ biologics are well tolerated, and patients can be treated for prolonged periods [12, 64, 65].
The most common side effects are injection-site skin reactions or infusion reactions. Mostly they are mild and transient local erythema, nodules, urticarial plaque, or pruritus. Patients on infliximab may develop hypersensitivity reactions such as generalized urticaria up to anaphylactic shock. Patients treated with adalimumab and infliximab have a higher frequency of upper respiratory tract infections, rhinitis, bronchitis, and urinary tract infections $[12,66,67]$. Since TNF- $\alpha$ plays an essential role in the host immune response against tuberculosis (TB), it is known that TNF- $\alpha$ inhibitors can increase the risk of TB. Therefore, screening of all patients for latent TB before therapy is mandatory. In addition, the presence of heart failure, hepatitis B infection, and malignancies should be ruled out before therapy is started $[65,66]$. Since biologics might have an effect on the immune response in neonates, it is contraindicated during pregnancy and women should use adequate contraceptives for up to at least five half-lives after the last dose. They are also contraindicated during lactation, since biologics are secreted in breast milk [3, 65, $66]$.

\subsection{Infliximab}

Infliximab is a chimeric monoclonal antibody consisting of the human IgG1 still containing a murine fragment of the antigen-biding (Fab) portion specific for TNF- $\alpha$. It binds to the soluble and transmembrane forms of TNF- $\alpha$, inhibiting TNF- $\alpha$ from binding to its receptors [68]. Multiple studies have reported on the efficacy of infliximab in patients with HS [69-71]. Mostly the same dose is given as in psoriasis, with $5 \mathrm{mg} / \mathrm{kg}$ infliximab at weeks 0,2 , and 6 , and continued every 8 weeks thereafter [3, 72]. Even though an improvement is often reported in the inflammatory lesions during infliximab therapy, recurrence is also high during therapy. Up to $50 \%$ develop new lesions after a treatment period of 37 weeks [69-71]. Moriatry et al. [71] suggested that an 8-week interval is too long for HS patients and that a 4-week interval is more effective [71], because most patients report a gradual increase in inflammatory lesions around 6 weeks after infusion. In our experience, a 6-week interval maintenance scheme works well in most HS patients. Shorter intervals for infliximab infusions are not recommended because they generally lead to more side effects and because of the cost aspects. Unfortunately, no trials have been done comparing different interval schemes of infliximab in patients with HS.

\subsection{Adalimumab}

Adalimumab is a fully human recombinant IgG1 monoclonal antibody against TNF- $\alpha$. It binds soluble TNF- $\alpha$ and thereby prevents its interaction with TNFR1- and TNFR2- 
type cell receptors [66]. In addition, it changes levels of adhesion molecules responsible for leucocyte migration, and reduces serum concentrations of C-reactive protein, erythrocyte sedimentation rate, and IL-6 [66].

The first reports of the use of adalimumab in HS patients dates from 2006 [73, 74]. Initially it showed efficacy in an African American male with concomitant seronegative arthritis [73] and later in a Caucasian male with concomitant inflammatory bowel disease [74]. Over the years multiple studies followed, reporting different clinical outcomes. Two prospective studies using a dose of $40 \mathrm{mg}$ every other week showed initial improvement $[75,76]$. However, after 12 weeks of treatment no difference could be observed compared with baseline or with placebo. Nonetheless, these studies report on high recurrence rates after discontinuation [75, 76]. It has been suggested that a weekly dose is more effective [3]. In a retrospective study Blanco et al. [64] initially started with $40 \mathrm{mg}$ every other week, but in five of the six patients the dose had to be increased to $40 \mathrm{mg}$ every week to prevent relapse. In a large prospective randomized placebo-controlled trial, $40 \mathrm{mg}$ adalimumab weekly was more effective than $40 \mathrm{mg}$ every other week or placebo after 16 weeks of treatment [12]. However, of the weekly patients, only $18 \%$ achieved the clinical end-point (clear, moderate to mild response with a decrease of at least two grades). This response rate dropped further when at 16 weeks the dose was decreased to $40 \mathrm{mg}$ every other week. Therefore, a high-dose regimen seem to be needed to suppress HS [12].

\subsubsection{Infliximab vs. Adalimumab}

Only one retrospective study compared the effectiveness of infliximab with adalimumab [77]. Ten patients were treated for 8 weeks with three courses of infliximab $5 \mathrm{mg} / \mathrm{kg}$, whereas in the other group, ten patients were treated for a year with adalimumab $40 \mathrm{mg}$ every other week. After 1 year the three courses of infliximab seemed more effective than continuous adalimumab [77]. However, it was not mentioned whether infliximab patients received other treatments during the follow-up period. In addition, as set out above, an every-other-week dosing regimen seems to be insufficient for HS.

\subsection{Etanercept}

Etanercept is a dimeric fusion protein consisting of the extracellular ligand-binding portion of the human p75 TNF receptor, and the constant portion of IgG1. Etanercept binds and neutralizes the soluble TNF, transmembrane $\mathrm{TNF}$, and lymphotoxin. In addition, it can alter dendriticcell, T-cell, and neutrophil emigration [65].
The first prospective open-label study of etanercept in HS showed promising results. Patients were treated with $50 \mathrm{mg}$ etanercept subcutaneously every week. After 12 weeks six out of ten patients showed a decrease of more than $50 \%$ in disease activity. This effect remained in the 12-week follow-up period [78]. However, in later openlabel and placebo-controlled studies, these results could not be reproduced $[79,80]$. In the open-label study 15 patients were treated with $50 \mathrm{mg}$ weekly. Only ten completed the 12-week treatment period, of whom three reached the primary end-point, a $50 \%$ reduction in the Physicians Global Assessment (PGA) score [79]. In the placebo-controlled trial, ten patients were treated with etanercept $50 \mathrm{mg}$ twice weekly and ten received placebo. After 12 weeks of treatment, there was no difference in PGA, patients' global assessment, or DLQI between etanercept and placebo. In addition, in the following 12-week openlabel phase, no improvement was observed [80]. Therefore, etanercept is not a first choice biologic in HS.

\subsection{Other Biological Treatments}

\subsubsection{Ustekinumab}

Ustekinumab is a human monoclonal antibody that binds to the p40 subunits of IL-12 and IL-23, preventing them from binding to their receptor [81]. To date, eight HS patients have been treated with $45 \mathrm{mg}$ ustekinumab subcutaneously, mostly at weeks 0,4 , and 12 , followed by every 3 months. Four patients showed a complete remission of their HS, three patients had a partial response, and one patient did not respond to ustekinumab treatment [82-85]. During the 23rd European Academy of Dermatology and Venereology (EADV) congress in 2014 in Amsterdam, Blok et al. [86] presented the results of the first prospective open-label study of ustekinumab in HS patients. Seventeen patients were treated with $45-90 \mathrm{mg}$, administered at weeks $0,4,16$, and 28 . Twelve patients completed the treatment protocol. A reduction of $\geq 50 \%$ in the modified Sartorius score was achieved by six patients $(35 \%)$ at week 40 , and another eight (47\%) showed a moderate response (reduction of $25-50 \%$ in the modified Sartorius score). Five patients dropped out because of a lack of efficacy, side effects, or psychological problems.

\subsubsection{Anakinra}

Anakinra is a recombinant human IL-1 receptor antagonist that blocks the inflammatory effects of IL-1 [87]. In HS elevated levels of IL-1 have been demonstrated in lesional and perilesional skin [17]. To date, ten patients have been treated with anakinra with mixed results [88-92]. In seven 
patients anakinra showed clear improvement of the HS lesions [88, 89, 92], whereas in the other three patients with severe HS, anakinra was ineffective $[90,91]$. We await results of a prospective, placebo-controlled trial with great interest to see the position of anakinra as a treatment option for HS.

\section{Other Anti-Inflammatory Drugs}

\subsection{Dapsone}

Dapsone is an aniline derivate from the sulfone group [93]. It not only has anti-microbial and antiprotozoal properties, but also anti-inflammatory properties similar to those of non-steroidal anti-inflammatory drugs (NSAIDs). In addition, it can suppress the levels of IL-8 and TNF- $\alpha$ [93]. To date, two retrospective studies have been published on the use of dapsone for HS. Kaur and Lewis [94] reviewed five cases of refractory HS treated with $50-150 \mathrm{mg}$ of dapsone per day. All five patients showed improvement after 4-12 weeks of treatment. In a later series of 24 patients treated with 50-200 mg per day, nine patients showed slight to clinically significant improvement, whereas the other 15 did not respond to dapsone therapy [95].

\subsection{Fumaric Acid Ester Derivatives (Fumarates)}

In Europe, fumarates are a common treatment for psoriasis because of their immunomodulatory and anti-inflammatory effects [72]. Among other multiple effects, they impair IL12 and IL-23 production by dendritic cells and macrophages [96]. Our department has recently reported on the use of fumarates in HS [97]. Seven patients with moderate to severe HS were treated with fumarates in a progressive dosage scheme up to $720 \mathrm{mg}$ a day. After 20 weeks of treatment only one patient showed clear improvement, but two others reported reduced inflammation and lesions that resolved faster. Therefore, treatment was continued and after 28 weeks all three showed slight to clear improvement. Two patients continued up to 1 year with clear improvement of their HS. However, four patients stopped after 20 weeks due to lack of efficacy and one patient stopped after 28 weeks because of persistent diarrhea [97].

\subsection{Cyclosporine}

Cyclosporine is a calcineurin inhibitor and a potent immunosuppressive drug [98]. It suppresses IL-2 production, and in the epidermis and dermis cyclosporine causes a depletion of lymphocytes and macrophages. It also inhibits the activation of $\mathrm{T}$ cells, natural killer cells, and antigenpresenting cells. In addition, cyclosporine can inhibit keratinocyte hyperproliferation [98]. To date, only a few cases have been reported on the use of cyclosporine in HS. Four patients with recalcitrant HS showed significant improvement after treatment with $3-5 \mathrm{mg} / \mathrm{kg}$ cyclosporine per day [99-101]. However, randomized controlled trials and larger case series are lacking on the effectiveness of cyclosporine in HS.

\subsection{Systemic and Intralesional Steroids}

Because of their anti-inflammatory and immunosuppressive properties, systemic steroids have always been widely used in dermatology. They are often mentioned as a treatment option for HS [3, 102, 103], and in a survey among physicians interested in HS from the UK, a quarter responded that prednisolone was one of their top ten treatment choices for HS [20]. A short-term treatment of $0.5-0.7 \mathrm{mg} / \mathrm{kg}$ can be used to control acute flares [3, 102]. However, reports on the use of oral steroids in HS date from more than 25 years ago, and no recent studies are available.

The use of intralesional corticosteroids is mostly based on clinical experience, but they are often used for solitary inflammatory nodules $[3,20]$. Intralesional injection of $5-10 \mathrm{mg} / \mathrm{ml}$ can cause a rapid reduction of the nodules and is in our opinion a good option for single recalcitrant inflammatory nodules $[3,22]$.

\subsection{Azathioprine}

Azathioprine is a purine antagonist with immunosuppressive, immunomodulating, and anti-inflammatory properties. In a small retrospective study of nine HS patients, azathioprine was ineffective in five patients, and the other three showed only slight improvement [104]. However, the therapeutic effects of azathioprine are normally reached after 2-3 months, and six patients were treated for 6 weeks or less due to side effects. In addition, the therapeutic range of azathioprine is $1-3 \mathrm{mg} / \mathrm{kg}$, but in five patients the dose remained below $1 \mathrm{mg} / \mathrm{kg}$. Therefore, it is possible that azathioprine was ineffective due to a too short a treatment duration and too low dosing [104].

\subsection{Colchicine}

The anti-inflammatory drug colchicine accumulates in neutrophils, inhibits neutrophil expression of cell adhesion molecules, and decreases neutrophil degranulation, chemotaxis, and phagocytosis $[105,106]$. In a small case series of eight HS patients, colchicine did not show any clinical improvement. Six patients dropped out before the end of the study because of lack of efficacy. Of the two patients who completed the 4-month period, only one showed slight improvement [106]. 


\subsection{Methotrexate}

Methotrexate is an anti-inflammatory and immunosuppressive drug that is often used for treating psoriasis, psoriatic arthritis, or rheumatoid arthritis [107]. In a report on three HS patients, a dose of $12.5-15 \mathrm{mg}$ per week did not have any effect on the existing lesions nor did it reduce the number of flare-ups [108].

\section{Retinoids}

\subsection{Isotretinoin}

The vitamin A derivate isotretinoin is naturally present in small amounts in the blood and tissue. It has an antiproliferative effect on sebocytes, inhibits cell differentiation and sebum secretion, and reduces the size of the sebaceous glands. In addition, it has anti-inflammatory, immunomodulatory, and antineoplastic properties [109]. The use of isotretinoin for HS comes from the former belief that HS is associated with acne vulgaris. However, in HS the sebaceous glands are not primarily affected and there is no evident seborrhea [110]. Even though multiple studies reported the lack of efficacy of isotretinoin in HS [111113], it is still often prescribed for this condition [20]. Blok et al. [114] reviewed seven papers in which isotretinoin was used for HS. In total, 174 patients were treated, of whom only 32 reported significant improvement (18\%), 30 moderate improvement $(17 \%)$, and in 112 patients no response was observed $(64 \%)$. Therefore, isotretinoin should not be prescribed for standard HS, and should only be considered if patients have concomitant acne vulgaris. Isotretinoin is highly teratogenic, therefore female patients should use adequate contraceptives up to 6 months after therapy, and pregnancy tests should routinely be performed.

\subsection{Acitretin}

Originally etretinate was the first retinoid registered for psoriasis, but its use was limited because of its unfavorable pharmacokinetic profile with a very long elimination time and teratogenic effects. It was later replaced by acitretin, which was derived from etretinate, but had a shorter halflife [115]. Acitretin has anti-inflammatory properties and modulates cellular differentiation, proliferation, and cornification of the epidermis $[115,116]$. Most importantly it influences the process of hyperkeratosis of the infundibular follicular epithelium, which is primary involved in the pathogenesis of HS $[13,14,116]$. In a retrospective study by Boer and Nazary [116], all 12 treated patients showed a positive response to $0.25-0.88 \mathrm{mg} / \mathrm{kg}$ acitretin for a period of $9-12$ months. Nine out of 12 patients achieved a marked or complete remission, whereas the other three had a mild to moderate response. All patients reported cheilitis as a side effect [116]. In a recent prospective study, 17 patients were treated with $0.5-0.6 \mathrm{mg} / \mathrm{kg}$ [117]. Nine patients completed the 9-month treatment period, of whom eight achieved the clinical endpoint, a reduction of $50 \%$ in the HS disease severity score (HSSI). Drop-out was mostly because of ineffectiveness or side effects [117]. Like isotretinoin, acitretin is teratogenic, and major human fetal abnormalities are associated with retinoid use during pregnancy. Female patients should use adequate contraceptives up to 2 years after discontinuation, since, especially in the presence of ethanol, acitretin converts to etretinate, which takes 2 years to be completely eliminated from the fatty tissue [115].

\subsection{Alitretinoin}

Alitretinoin is a vitamin A derivative and is registered for severe chronic hand eczema. Recently the first study on the use of alitretinoin in HS was published [118]. Fourteen patients were treated with $10 \mathrm{mg}$ alitretinoin daily for a period of 24 weeks. Six patients showed significant improvement, with a reduction of $50 \%$ in the Sartorius score. Another five patients reported improvement; however, this was less than a $50 \%$ reduction in the Sartorius score. Only three patients did not respond [118]. Alitretinoin is very similar to acitretin, except for its much shorter half-life, making it a better treatment option for female patients. Contraceptives have to be used up to 1 month after treatment discontinuation.

\section{Other Medical Treatments}

\subsection{Zinc}

Zinc plays a role in the innate and adaptive immunity. It is believed that zinc can alter the differentiation and function of $\mathrm{T}$ cells, and that it activates natural killer cells and the phagocytic function of granulocytes. In addition, it leads to an increased production of IL-6, IL- $1 \beta$, and TNF- $\alpha$ [119, 120]. In a pilot-study, 22 patients started with $90 \mathrm{mg}$ of zinc and the doses was reduced by $15 \mathrm{mg}$ every 2 months. Eight patients showed complete remission, and partial remission was achieved in the other 14 patients. Relapse occurred when doses lower than 30-60 mg were given. Gastrointestinal discomfort was the most common side effect and was reported by four patients [120]. 


\subsection{Metformin}

Metformin is an insulin sensitizer and is a first-line treatment option for patients with diabetes type II. Metformin also has anti-oxidative and anti-androgenic properties and has been shown to inhibit human immortalized keratinocytes in vitro $[121,122]$. Metformin was initially reported to have an effect on HS after a woman reported worsening of her HS after metformin was stopped [123]. In a prospective study, $25 \mathrm{HS}$ patients were treated with a progressive dose scheme up to a maximum of $500 \mathrm{mg}$ three times a day. Eighteen patients showed clinical improvement, with seven having a reduction of more than $50 \%$ in the Sartorius score. The other seven patients were unresponsive to the treatment. Only minor gastro-intestinal side effects were reported at the beginning of the treatment [122].

\section{Hormonal Treatment}

The role of sex hormones in the pathogenesis of HS is still under debate. The clinical course of HS would suggest a role of sex hormones, due to post-pubertal onset, female predisposition, reports of peri-menstrual flares, and improvement during pregnancies [25, 103, 124]. However, no difference was found in androgen levels between HS patients and body mass index (BMI)-matched controls [125].

\subsection{Finasteride}

Finasteride is a $5 \alpha$-reductase inhibitor that inhibits the conversion of testosterone to dihydrotestosterone [126]. It was originally approved for treatment of benign prostatic hypertrophy and later for androgenetic alopecia in men. To date, the use of finasteride has been reported in 12 HS patients-eight adults and four children. Seven adult patients showed a good response on $5 \mathrm{mg}$ finasteride daily after a treatment period of $2-12$ weeks $[127,128]$. Two patients showed recurrence 1 month after discontinuation. The four female children were treated with finasteride 1.25-10 mg daily with good effect. However, all received additional treatment with oral contraceptives, antibiotics, or surgery $[128,129]$.

Side effects of finasteride in men are decreased libido and gynecomastia. Finasteride should not be used during pregnancy due to feminization of the male fetus [126].

\subsection{Cyproterone Acetate}

In 1986, Sawers et al. [130] reported on the effectiveness of the antiandrogen cyproterone acetate combined with estrogen in four female HS patients. However, a double- blind controlled trial comparing ethinyloestradiol $50 \mu \mathrm{g} /$ cyproterone $50 \mathrm{mg}$ with ethinyloestradiol $50 \mu \mathrm{g} /$ norgestrel $500 \mu \mathrm{g}$ showed no difference between the two groups. However, of the 18 patients from both groups that completed the trial, 12 showed a good response, suggesting that both hormonal therapies can be effective in HS [131]. However, larger, well powered studies on the use of hormonal therapy in HS are lacking.

\section{Pain Management}

Pain management is a crucial part of the treatment of HS. However, no studies are available on the use of analgesics in HS, and only two reviews have been published on pain management in HS patients [132, 133]. Even though these are comprehensive reviews on a broad spectrum of analgesics, its use in HS is mostly based on clinical experience $[132,133]$. First of all it is recommended that a visual analogue scale is used to assess the pain level of the patients, and this can also be a guide to evaluate if the prescribed analgesics are sufficient. For moderate constant pain, oral acetaminophen (paracetamol) $1000 \mathrm{mg}$ four times per day is often the first step in pain treatment. In general, acetaminophen is well tolerated; however, excessive doses can lead to liver toxicity [132, 133]. When acetaminophen does not sufficiently reduce the level of pain, or when the patient complains of sporadic acute pain, NSAIDs are indicated. The dose depends on which NSAID is chosen, and standard regimens are recommended [3]. There is no evidence that one NSAID is superior to another $[132,133]$. Long-term use of NSAIDs can increase the risk of gastric ulcers, therefore proton pump inhibitors are recommended when patients use NSAIDs on a frequent basis. When patients have high levels of chronic pain, opiates are indicated [3]. Codeine is the first option of this drug class, due to its lower risk of addiction. When higher levels of pain medication are needed, referral to a pain team is recommended [132].

\section{Lifestyle Changes}

Smoking and obesity are strong risk factors for HS. Most HS patients are active smokers (66-71\%) or ex-smokers $(8-15 \%)$, and $51-82 \%$ of patients are overweight or obese, with a BMI $>25 \mathrm{~kg} / \mathrm{m}^{2}$ [134-137]. Disease severity is positively correlated with BMI [134-136], and case reports have demonstrated remission of HS after extensive weight loss $[138,139]$. In one study patients were asked after bariatric surgery if they had suffered from HS before the operation and if the symptoms had changed after the operation. After a decrease in BMI of $15 \%$, half of the 
patients stated they were free of inflammation and another $20 \%$ reported to have fewer symptoms [140]. Since HS is also associated with the metabolic syndrome [141], patients with HS should be strongly advised to reduce weight.

The exact effect of smoking cessation on HS is still unclear. However, it is thought that smoking can trigger the onset of HS, and heavy smokers tend to have more severe disease than non- or mild smokers [134-136]. In a study on the clinical course, patients were asked 22 years after the diagnosis was made if they still suffered from HS. Nonsmokers and ex-smokers were more often disease-free than active smokers, indicating that smoking cessation contributes to disease remission. This is supported by a case report of two patients who became free of symptoms after they quitted smoking. However, mostly cessation does not give instant improvement of the disease [142], often leading to disappointment in the patients and causing them to restart smoking. Patients should be well educated that they should not expect instant relief after cessation but that it helps towards improvement or even remission over the years. We believe that active referral of patients with HS to their GP or any other "stopping smoking" and/or "weight loss" programme is essential.

\section{Future Options}

Recently, elevated levels of IL-17 and IL-23 have been found in lesional HS skin [18, 19]. These findings point towards new treatment options. Biologics targeting IL-17 are secukinumab, ixekizumab, and brodalumab. Secukinumab is a fully human IgG1 monoclonal antibody against IL-17A, whereas ixekizumab is a humanized IgG4 monoclonal antibody that neutralizes IL-17A, and brodalumab is human $\mathrm{IgG} 2$ monoclonal antibody that blocks IL-17R, a receptor subunit shared by IL-17A, IL$17 \mathrm{~F}$, and IL17A/F heterodimer ligands [143, 144]. It is also possible to target IL-23 alone, with tildrakizumab or guselkumab. Tildrakizumab is a humanized IgG1k monoclonal antibody against IL-23p19, whereas it does not bind to IL-12 or the p40 subunit, just like guselkumab, which is a human IgG1 monoclonal antibody against IL-23p19 [143].

Another immunomodulating drug is apremilast. It is a selective inhibitor of phosphodiesterase 4 , and has been shown in vivo to inhibit the production of the pro-inflammatory cytokines (e.g., IL-2, IL-5, IL-12A, IL-13, IL-17 IL-23A, TNF- $\alpha$, INF- $\alpha$, and INF- $\gamma$ ), and chemokines (e.g., CXCL9 and CXCL10) [145].

Even though these therapeutic options have been shown to be effective in psoriasis [143-145], no studies are available on their use in HS.

\section{Conclusion}

Hidradenitis suppurativa is a chronic inflammatory skin disease. Over the years multiple treatment options for HS have been suggested; however, so far none has been curative for HS. In mild disease, clindamycin lotion or resorcinol cream can give long-term remission. When these are insufficient or in more severe HS, mostly tetracyclines are first-line systemic options. However, the combination of clindamycin with rifampicin is the best-documented antibiotic treatment for HS and is often effective in moderate to severe HS. Although antibiotics can be effective in reducing the number of inflamed lesions, the recurrence rate is high after discontinuation. A more long-term treatment option is possible using retinoids, especially acitretin; however, due to their teratogenicity, they are less useful for females in the reproductive age. When patients fail to respond to most common treatments, biologics (e.g., infliximab or adalimumab) are the next step. Multiple antiinflammatory drugs have been suggested for HS, such as dapsone, fumarates, or cyclosporine. However, their effectiveness in HS is based on small case series with varying results. Although not addressed in this review, surgical interventions are often needed to achieve remission, especially when sinus tracts or scarring are present. For each patient treatment should be chosen based on the clinical presentation of the HS and the preferences of the patient.

\section{Compliance with Ethical Standards}

Funding sources None.

Conflict of interest Inge E. Deckers has no conflicts of interest to declare. Errol P. Prens has received honoraria from AbbVie, Amgen, Celgene, Janssen, Galderma, Novartis, and Pfizer for participation as a speaker, has been on advisory boards, and received investigator initiated grants (paid to the Erasmus MC) from AbbVie, AstraZeneca, Janssen, and Pfizer.

\section{References}

1. Jemec GBE. Clinical practice. Hidradenitis suppurativa. N Engl J Med. 2012;366:158-64.

2. Revuz JE. Hidradenitis suppurativa. J Eur Acad Dermatol Venereol. 2009;23:985-98.

3. Zouboulis CC, Desai N, Emtestam L, Hunger RE, Ioannides D, Juhász I, et al. European S1 guideline for the treatment of hidradenitis suppurativa/acne inversa. J Eur Acad Dermatol Venereol. 2015;29:619-44.

4. Deckers IE, van der Zee HH, Boer J, Prens EP. Correlation of early-onset hidradenitis suppurativa with stronger genetic susceptibility and more widespread involvement. J Am Acad Dermatol. 2015;72:485-8.

5. Bettoli V, Ricci M, Zauli S, Virgili A. Hidradenitis suppurativaacne inversa: a relevant dermatosis in pediatric age. Br J Dermatol. 2015 (Epub ahead). 
6. Cosmatos I, Matcho A, Weinstein R, Montgomery MO, Stang P. Analysis of patient claims data to determine the prevalence of hidradenitis suppurativa in the United States. J Am Acad Dermatol. 2013;68:412-9.

7. Jemec GBE, Heidenheim M, Nielsen NH. The prevalence of hidradenitis suppurativa and its potential precursor lesions. J Am Acad Dermatol. 1996;35:191-4.

8. Revuz JE, Canoui-Poitrine F, Wolkenstein P, Viallette C, Gabison G, Pouget F, et al. Prevalence and factors associated with hidradenitis suppurativa: results from two case-control studies. J Am Acad Dermatol. 2008;59:596-601.

9. Hurley HJ. Axillary hyperhidrosis, apocrine bromhidrosis, hidradenitis suppurativa, and familial benign pemphigus: surgical approaches. In: Roenigh R, Roenigh H, editors. Dermatogic Surgery. New York: Marcel Dekker; 1989. p. 729-39.

10. Sartorius K, Lapins J, Emtestam L. Jemec GBE. Suggestions for uniform outcome variables when reporting treatment effects in hidradenitis suppurativa. Br J Dermatol. 2003;149:211-3.

11. Canoui-Poitrine F, Revuz JE, Wolkenstein P, Viallette C, Gabison G, Pouget F, et al. Clinical characteristics of a series of 302 French patients with hidradenitis suppurativa, with an analysis of factors associated with disease severity. J Am Acad Dermatol. 2009;61:51-7.

12. Kimball AB, Kerdel F, Adams D, Mrowietz U, Gelfand JM, Gniadecki R, et al. Adalimumab for the treatment of moderate to severe hidradenitis suppurativa: a parallel randomized trial. Ann Intern Med Am Coll Phys. 2012;157:846-55.

13. Yu C-W, Cook MG. Hidradenitis suppurativa: a disease of follicular epithelium, rather than apocrine glands. Br J Dermatol. 1990;122:763-9.

14. Boer J, Weltevreden EF. Hidradenitis suppurativa or acne inversa. A clinicopathological study of early lesions. Br J Dermatol. 1996;135:721-5.

15. von Laffert M, Helmbold P, Wohlrab J, Fiedler E, Stadie V, Marsch WC. Hidradenitis suppurativa (acne inversa): early inflammatory events at terminal follicles and at interfollicular epidermis. Exp Dermatol. 2010;19:533-7.

16. Von Laffert M, Stadie V, Wohlrab J, Marsch WC. Hidradenitis suppurativa/acne inversa: bilocated epithelial hyperplasia with very different sequelae. Br J Dermatol. 2011;164:367-71.

17. van der Zee HH, de Ruiter L, van den Broecke DG, Dik WA, Laman JD, Prens EP. Elevated levels of tumour necrosis factor (TNF)- $\alpha$, interleukin (IL)-1 $\beta$ and IL-10 in hidradenitis suppurativa skin: a rationale for targeting TNF- $\alpha$ and IL-1 $\beta$. Br J Dermatol. 2011;164:1292-8.

18. Schlapbach C, Hänni T, Yawalkar N, Hunger RE. Expression of the IL-23/Th17 pathway in lesions of hidradenitis suppurativa. J Am Acad Dermatol. 2011;65:790-8.

19. Kelly G, Hughes R, Mc Garry T, van den Born M, Adamzik K, Fitzgerald R, et al. Dysregulated cytokine expression in lesional and non-lesional skin in Hidradenitis suppurativa. Br J Dermatol. 2015 (Epub ahead).

20. Ingram JR, McPhee M. Management of hidradenitis suppurativa: a UK survey of current practice. $\mathrm{Br} \mathrm{J}$ Dermatol. 2015;173:1070-2.

21. Clemmensen OJ. Topical treatment of hidradenitis suppurativa with clindamycin. Int J Dermatol. 1983;22:325-8.

22. Sartorius K, Boer J, Jemec GBE. Topical treatment. Hidradenitis suppurativa. Berlin: Springer; 2006. p. 150-60.

23. Boer J, Jemec GBE. Resorcinol peels as a possible self-treatment of painful nodules in hidradenitis suppurativa. Clin Exp Dermatol. 2010;35:36-40.

24. Detmar M, Mayer-da-Silva A, Stadler R, Orfanos CE. Effects of azelaic acid on proliferation and ultrastructure of mouse keratinocytes in vitro. J Invest Dermatol. 1989;93:70-4.
25. Deckers IE, van der Zee HH, Prens EP. Epidemiology of hidradenitis suppurativa: prevalence, pathogenesis, and factors associated with the development of HS. Curr Dermatol Rep. 2014;3:54-60.

26. Jemec GBE, Faber M, Gutschik E, Wendelboe P. The bacteriology of hidradenitis suppurativa. Dermatology. 1996;193:203-6.

27. Lapins J, Jarstrand C, Emtestam L. Coagulase-negative staphylococci are the most common bacteria found in cultures from the deep portions of hidradentis suppurativa lesions, as obtained by carbon dioxide laser surgery. $\mathrm{Br} \mathrm{J}$ Dermatol. 1999;140:90-5.

28. Sartorius K, Killasli H, Oprica C, Sullivan A, Lapins J. Bacteriology of hidradenitis suppurativa exacerbations and deep tissue cultures obtained during carbon dioxide laser treatment. Br J Dermatol. 2012;166:879-83.

29. Matusiak Ł, Bieniek A, Szepietowski JC. Bacteriology of hidradenitis suppurativa-which antibiotics are the treatment of choice? Acta Derm Venereol. 2014;94:699-702.

30. Nikolakis G, Join-Lambert O, Karagiannidis I, Guet-Revillet H, Zouboulis CC, Nassif A. Bacteriology of hidradenitis suppurativa/acne inversa: a review. J Am Acad Dermatol. 2015;73:S12-8.

31. Ring HC, Riis Mikkelsen P, Miller IM, Jenssen H, Fuursted K, Saunte DM, et al. The bacteriology of hidradenitis suppurativa: a systematic review. Exp Dermatol. 2015;24:727-31.

32. Guet-Revillet H, Coignard-Biehler H, Jais J-P, Quesne G, Frapy E, Poirée S, et al. Bacterial pathogens associated with hidradenitis suppurativa, France. Emerg Infect Dis. 2014;20:1990-8.

33. Collier F, Smith RC, Morton CA. Diagnosis and management of hidradenitis suppurativa. BMJ. 2013;346:f2121.

34. Pasquale TR, Tan JS. Nonantimicrobial effects of antibacterial agents. Clin Infect Dis. 2005;40:127-35.

35. Sapadin AN, Fleischmajer R. Tetracyclines: nonantibiotic properties and their clinical implications. J Am Acad Dermatol. 2006;54:258-65.

36. Monk E, Shalita A, Siegel DM. Clinical applications of nonantimicrobial tetracyclines in dermatology. Pharmacol Res. 2011;63:130-45.

37. Jemec GBE, Wendelboe P. Topical clindamycin versus systemic tetracycline in the treatment of hidradenitis suppurativa. J Am Acad Dermatol. 1998;39:971-4.

38. Simonart T, Dramaix M, De Maertelaer V. Efficacy of tetracyclines in the treatment of acne vulgaris: a review. Br J Dermatol. 2008;158:208-16.

39. Nahum GG, Uhl K, Kennedy DL. Antibiotic use in pregnancy and lactation: what is and is not known about teratogenic and toxic risks. Obstet Gynecol. 2006;107:1120-38.

40. Leigh DA. Antibacterial activity and pharmacokinetics of clindamycin. J Antimicrob Chemother. 1981;7:3-9.

41. Van Vlem B, Vanholder R, De Paepe P, Ringoir S, Vogelaers D. Immunomodulating effects of antibiotics: literature review. Infection. 1996;24:275-91.

42. Tufano MA, Cipollaro de l'Ero G, Ianniello R, Baroni A, Galdlero F. Antimicrobial agents induce monocytes to release IL$1 \alpha$, IL- 6 , and TNF and induce lymphocytes to release IL-4 and TNF $\tau$. Immunopharmacol Immunotoxicol. 1992;14:769-82.

43. Sensi P. History of the development of rifampin. Rev Infect Dis. 1983;5:S402-6.

44. Tsankov N, Angelova I. Rifampin in dermatology. Clin Dermatol. 2003;21:50-5.

45. Ziglam HM, Daniels I, Finch RG. Immunomodulating activity of rifampicin. J Chemother. 2004;16:357-61.

46. Mendonça CO. Griffiths CEM. Clindamycin and rifampicin combination therapy for hidradenitis suppurativa. $\mathrm{Br} \mathrm{J}$ Dermatol. 2006;154:977-8. 
47. Gener G, Canoui-Poitrine F, Revuz JE, Faye O, Poli F, Gabison $\mathrm{G}$, et al. Combination therapy with clindamycin and rifampicin for hidradenitis suppurativa: a series of 116 consecutive patients. Dermatology. 2009;219:148-54.

48. van der Zee HH, Boer J, Prens EP, Jemec GBE. The effect of combined treatment with oral clindamycin and oral rifampicin in patients with hidradenitis suppurativa. Dermatology. 2009;219:143-7.

49. Bettoli V, Zauli S, Borghi A, Toni G, Minghetti S, Ricci M, et al. Oral clindamycin and rifampicin in the treatment of hidradenitis suppurativa-acne inversa: a prospective study on 23 patients. J Eur Acad Dermatol Venereol. 2014;28:125-6.

50. Renneberg J, Karlsson E, Nilsson B, Walder M. Interactions of drugs acting against Staphylococcus aureus in vitro and in a mouse model. J Infect. 1993;26:265-77.

51. Join-Lambert O, Ribadeau-Dumas F, Jullien V, Kitzis M-D, Jais $\mathrm{J}-\mathrm{P}$, Coignard-Biehler $\mathrm{H}$, et al. Dramatic reduction of clindamycin plasma concentration in hidradenitis suppurativa patients treated with the rifampin-clindamycin combination. Eur J Dermatol. 2014;24:94-5.

52. Bernard A, Kermarrec G, Parize P, Caruba T, Bouvet A, Mainardi J-L, et al. Dramatic reduction of clindamycin serum concentration in staphylococcal osteoarticular infection patients treated with the oral clindamycin-rifampicin combination. J Infect. 2015;71:200-6.

53. Curis E, Pestre V, Jullien V, Eyrolle L, Archambeau D, Morand $\mathrm{P}$, et al. Pharmacokinetic variability of clindamycin and influence of rifampicin on clindamycin concentration in patients with bone and joint infections. Infection. 2015;43:473-81.

54. Join-Lambert O, Coignard H, Jais J, Guet-Revillet H, Poiree S, Fraitag S, et al. Efficacy of rifampin-moxifloxacin-metronidazole combination therapy in hidradenitis suppurativa. Dermatology. 2011;222:49-58.

55. Lamp KC, Freeman CD, Klutman NE, Lacy MK. Pharmacokinetics and pharmacodynamics of the nitroimidazole antimicrobials. Clin Pharmacokinet. 1999;36:353-73.

56. Shakir L, Javeed A, Ashraf M, Riaz A. Metronidazole and the immune system. Pharmazie. 2011;66:393-8.

57. Muijsers RBR, Jarvis B. Moxifloxacin. Drugs. 2002;62:967-73.

58. Dalhoff A. Immunomodulatory activities of fluoroquinolones. Infection. 2005;33:55-70.

59. Cação G, Fontes S, Salgado M, Rodrigues T, Damásio J. Metronidazole-induced central and peripheral nervous system toxicity. Neurol Sci. 2015;36:1737-9.

60. Kuriyama A, Jackson JL, Doi A, Kamiya T. Metronidazoleinduced central nervous system toxicity: a systematic review. Clin Neuropharmacol. 2011;34:241-7.

61. Martínez F, Nos P, Benlloch S, Ponce J. Hidradenitis suppurativa and Crohn's disease: response to treatment with infliximab. Inflamm Bowel Dis. 2001;7:323-6.

62. Katsanos KH, Christodoulou DK, Tsianos EV. Axillary hidradenitis suppurativa successfully treated with infliximab in a Crohn's disease patient. Am J Gastroenterol. 2002;97:2155-6.

63. Kirby JS, Miller JJ, Adams DR, Leslie D. Health care utilization patterns and costs for patients with hidradenitis suppurativa. JAMA Dermatol. 2014;150:937-44.

64. Blanco R, Martínez-Taboada VM, Villa I, González-Vela MC, Fernández-Llaca $\mathrm{H}$, Agudo $\mathrm{M}$, et al. Long-term successful adalimumab therapy in severe hidradenitis suppurativa. Arch Dermatol. 2009;145:580-4.

65. Kerensky TA, Gottlieb AB, Yaniv S, Au S. Etanercept: efficacy and safety for approved indications. Expert Opin Drug Saf. 2012;11:121-39.

66. Traczewski P, Rudnicka L. Adalimumab in dermatology. Br J Clin Pharmacol. 2008;66:618-25.
67. Mrowietz U, Reich K. Ten years of infliximab: its role in dermatology. Eur J Pharmacol. 2009;623:S10-6.

68. Castelo-Soccio L, Van Voorhees AS. Long-term efficacy of biologics in dermatology. Dermatol Ther. 2009;22:22-33.

69. Grant A, Gonzalez T, Montgomery MO, Cardenas V, Kerdel FA. Infliximab therapy for patients with moderate to severe hidradenitis suppurativa: a randomized, double-blind, placebocontrolled crossover trial. J Am Acad Dermatol. 2010;62:205-17.

70. Paradela S, Rodríguez-Lojo R, Fernández-Torres R, Arévalo P, Fonseca E. Long-term efficacy of infliximab in hidradenitis suppurativa. J Dermatol Treat. 2012;23:278-83.

71. Moriarty B, Jiyad Z, Creamer D. Four-weekly infliximab in the treatment of severe hidradenitis suppurativa. $\mathrm{Br} \mathrm{J}$ Dermatol. 2014;170:986-7.

72. Pathirana D, Ormerod AD, Saiag P, Smith C, Spuls PI, Nast A, et al. European S3-guidelines on the systemic treatment of psoriasis vulgaris. J Eur Acad Dermatol Venereol. 2009;23:1-70.

73. Scheinfeld N. Treatment of coincident seronegative arthritis and hidradentis supprativa with adalimumab. J Am Acad Dermatol. 2006;55:163-4.

74. Moul DK, Korman NJ. Severe hidradenitis suppurativa treated with adalimumab. Arch Dermatol. 2006;142:1110-2.

75. Miller I, Lynggaard CD, Lophaven S, Zachariae C, Dufour DN, Jemec GBE. A double-blind placebo-controlled randomized trial of adalimumab in the treatment of hidradenitis suppurativa. Br J Dermatol. 2011;165:391-8.

76. Amano M, Grant A, Kerdel FA. A prospective open-label clinical trial of adalimumab for the treatment of hidradenitis suppurativa. Int J Dermatol. 2010;49:950-5.

77. van Rappard DC, Leenarts MFE, Meijerink-van't Oost L, Mekkes JR. Comparing treatment outcome of infliximab and adalimumab in patients with severe hidradenitis suppurativa. J Dermatol Treat. 2012;23:284-9.

78. Giamarellos-Bourboulis EJ, Pelekanou E, Antonopoulou A, Petropoulou H, Baziaka F, Karagianni V, et al. An open-label phase II study of the safety and efficacy of etanercept for the therapy of hidradenitis suppurativa. $\mathrm{Br} \quad \mathrm{J}$ Dermatol. 2008;158:567-72.

79. Lee RA, Dommasch E, Treat J, Sciacca-Kirby J, Chachkin S, Williams $J$, et al. A prospective clinical trial of open-label etanercept for the treatment of hidradenitis suppurativa. J Am Acad Dermatol. 2009;60:565-73.

80. Adams DR, Yankura JA, Fogelberg AC, Anderson BE. Treatment of hidradenitis suppurativa with etanercept injection. Arch Dermatol. 2010;146:501-4.

81. Sehgal VN, Pandhi D, Khurana A. Biologics in dermatology: an integrated review. Indian J Dermatol. 2014;59:425-41.

82. Gulliver WP, Jemec GBE, Baker KA. Experience with ustekinumab for the treatment of moderate to severe hidradenitis suppurativa. J Eur Acad Dermatol Venereol. 2012;26:911-4.

83. Baerveldt EM, Kappen JH, Thio HB, van Laar JAM, van Hagen PM, Prens EP. Successful long-term triple disease control by ustekinumab in a patient with Behçet's disease, psoriasis and hidradenitis suppurativa. Ann Rheum Dis. 2013;72:626-7.

84. Sharon VR, Garcia MS, Bagheri S, Goodarzi H, Yang C, Ono Y, et al. Management of recalcitrant hidradenitis suppurativa with ustekinumab. Acta Derm Venereol. 2012;92:320-1.

85. Santos-Pérez MI, García-Rodicio S, del Olmo-Revuelto MA, Pozo-Román T. Ustekinumab for hidradenitis suppurativa: a case report. Actas Dermosifiliogr. 2014;105:720-2.

86. Blok JL, Li K, Brodmerkel C, Horvátovich P, Jonkman MF, Horváth $\mathrm{B}$. Ustekinumab in hidradenitis suppurativa: a clinical open label study with analyses of the protein expression profile 
in serum. FCO3.8. 23rd European Academy of Dermatology Congress, Amsterdam, Oct 8-12, 2014.

87. Pazyar N, Feily A, Yaghoobi R. An overview of interleukin-1 receptor antagonist, anakinra, in the treatment of cutaneous diseases. Curr Clin Pharmacol. 2012;7:271-5.

88. Hsiao JL, Antaya RJ, Berger T, Maurer T, Shinkai K, Leslie KS. Hidradenitis suppurativa and concomitant pyoderma gangrenosum: a case series and literature review. Arch Dermatol. 2010;146:1265-70.

89. Zarchi K, Dufour DN, Jemec GBE. Successful treatment of severe hidradenitis suppurativa with anakinra. JAMA Dermatol. 2013;149:1192-4.

90. Van der Zee HH, Prens EP. Failure of anti-interleukin-1 therapy in severe hidradenitis suppurativa: a case report. Dermatology. 2013;226:97-100.

91. Menis D, Maroñas-Jiménez L, Delgado-Marquez AM, PostigoLlorente C, Vanaclocha-Sebastián F. Two cases of severe hidradenitis suppurativa with failure of anakinra therapy. Br J Dermatol. 2015;172:810-1.

92. Leslie K, Tripathi S, Nguyen T, Pauli M, Rosenblum M. An open-label study of anakinra for the treatment of moderate to severe hidradenitis suppurativa. J Am Acad Dermatol. 2014;70:243-51.

93. Wozel G, Blasum C. Dapsone in dermatology and beyond. Arch Dermatol Res. 2014;306:103-24.

94. Kaur MR, Lewis HM. Hidradenitis suppurativa treated with dapsone: a case series of five patients. J Dermatol Treat. 2006;17:211-3.

95. Yazdanyar S, Boer J, Ingvarsson G, Szepietowski JC, Jemec GBE. Dapsone therapy for hidradenitis suppurativa: a series of 24 patients. Dermatology. 2011;222:342-6.

96. Ghoreschi K, Brück J, Kellerer C, Deng C, Peng H, Rothfuss O, et al. Fumarates improve psoriasis and multiple sclerosis by inducing type II dendritic cells. J Exp Med. 2011;208:2291-303.

97. Deckers IE, Zee HH, Balak DMW, Prens EP. Fumarates, a new treatment option for therapy-resistant hidradenitis suppurativa: a prospective open-label pilot study. $\mathrm{Br} \mathrm{J}$ Dermatol. 2015;172:828-9.

98. Amor KT, Ryan C, Menter A. The use of cyclosporine in dermatology: part I. J Am Acad Dermatol. 2010;63:925-46.

99. Buckley DA, Rogers S. Cyclosporin-responsive hidradenitis suppurativa. J R Soc. 1995;88:289P-90P.

100. Rose R, Goodfield M, Clark S. Treatment of recalcitrant hidradenitis suppurativa with oral cyclosporin. Clin Exp Dermatol. 2006;31:154-5.

101. Bianchi L, Hansel K, Stingeni L. Recalcitrant severe hidradenitis suppurativa successfully treated with cyclosporine A. J Am Acad Dermatol. 2012;67:e278-9.

102. Nybæk H, Jemec GBE. Immunosuppressive therapy in hidradenitis suppurativa. Hidradenitis Suppurativa. Berlin: Springer; 2006. p. 136-40.

103. Alikhan A, Lynch PJ, Eisen DB. Hidradenitis suppurativa: a comprehensive review. J Am Acad Dermatol. 2009;60:539-61.

104. Nazary M, Prens EP, Boer J. Azathioprine lacks efficacy in hidradenitis suppurativa: a retrospective study of 9 patients. Br J Dermatol. 2015 (Epub ahead).

105. Cocco G, Chu DCC, Pandolfi S. Colchicine in clinical medicine. A guide for internists. Eur J Intern Med. 2010;21:503-8.

106. Van der Zee HH, Prens EP. The anti-inflammatory drug colchicine lacks efficacy in hidradenitis suppurativa. Dermatology. 2011;223:169-73.

107. Yélamos O, Puig L. Systemic methotrexate for the treatment of psoriasis. Expert Rev Clin Immunol. 2015;11:553-63.

108. Jemec GBE. Methotrexate is of limited value in the treatment of hidradenitis suppurativa. Clin Exp Dermatol. 2002;27:528-9.
109. Nickle SB, Peterson N, Peterson M. Updated Physician's Guide to the off-label uses of oral isotretinoin. J Clin Aesthet Dermatol. 2014;7:22-34.

110. Jemec GBE, Hansen U. Histology of hidradenitis suppurativa. J Am Acad Dermatol. 1996;34:994-9.

111. Norris JFB, Cunliffe WJ. Failure of treatment of familial widespread hidradenitis suppurativa with isotretinoin. Clin Exp Dermatol. 1986;11:579-83.

112. Boer J, van Gemert MJP. Long-term results of isotretinoin in the treatment of 68 patients with hidradenitis suppurativa. J Am Acad Dermatol. 1999;40:73-6.

113. Soria A, Canoui-Poitrine F, Wolkenstein P, Poli F, Gabison G, Pouget F, et al. Absence of efficacy of oral isotretinoin in hidradenitis suppurativa: a retrospective study based on patients' outcome assessment. Dermatology. 2009;218:134-5.

114. Blok JL, van Hattem S, Jonkman MF, Horváth B. Systemic therapy with immunosuppressive agents and retinoids in hidradenitis suppurativa: a systematic review. Br J Dermatol. 2013;168:243-52.

115. Lee CS, Koo J. A review of acitretin, a systemic retinoid for the treatment of psoriasis. Expert Opin Pharmacother. 2005;6:1725-34.

116. Boer J, Nazary M. Long-term results of acitretin therapy for hidradenitis suppurativa. Is acne inversa also a misnomer? Br J Dermatol. 2011;164:170-5.

117. Matusiak Ł, Bieniek A, Szepietowski JC. Acitretin for hidradenitis suppurativa treatment: a prospective series of 17 patients. Br J Dermatol. 2014;171:170-4.

118. Verdolini R, Simonacci F, Menon S, Pavlou P, Mannello B. Alitretinoin: a useful agent in the treatment of hidradenitis suppurativa, especially in women of child-bearing age. G Ital Dermatol Venereol. 2015;150:155-62.

119. Brocard A, Dréno B. Innate immunity: a crucial target for zinc in the treatment of inflammatory dermatosis. J Eur Acad Dermatol Venereol. 2011;25:1146-52.

120. Brocard A, Knol A, Khammari A, Dréno B. Hidradenitis suppurativa and zinc: a new therapeutic approach. Dermatology. 2007;214:325-7.

121. Badr D, Kurban M, Abbas O. Metformin in dermatology: an overview. J Eur Acad Dermatol Venereol. 2013;27:1329-35.

122. Verdolini R, Clayton N, Smith A, Alwash N, Mannello B. Metformin for the treatment of hidradenitis suppurativa: a little help along the way. J Eur Acad Dermatol Venereol. 2013;27:1101-8.

123. Arun B, Loffeld A. Long-standing hidradenitis suppurativa treated effectively with metformin. Clin Exp Dermatol. 2009;34:920-1.

124. Jemec GBE. The symptomatology of hidradenitis suppurativa in women. Br J Dermatol. 1988;119:345-50.

125. Barth JH, Layton AM, Cunliffe WJ. Endocrine factors in preand postmenopausal women with hidradenitis suppurativa. Br J Dermatol. 1996;134:1057-9.

126. Libecco JF, Bergfeld WF. Finasteride in the treatment of alopecia. Expert Opin Pharmacother. 2004;5:933-40.

127. Farrell AM, Randall VA, Vafaee T. Dawber RPR. Finasteride as a therapy for hidradenitis suppurativa. $\mathrm{Br} \mathrm{J}$ Dermatol. 1999;141:1136-52.

128. Joseph MA, Jayaseelan E, Ganapathi B, Stephen J. Hidradenitis suppurativa treated with finasteride. J Dermatol Treat. 2005; $16: 75-8$.

129. Randhawa HK, Hamilton J, Pope E. Finasteride for the treatment of hidradenitis suppurativa in children and adolescents. JAMA Dermatol. 2013;149:732-5.

130. Sawers RS, Randall VA, Ebling FJ. Control of hidradenitis suppurativa in women using combined antiandrogen 
(cyproterone acetate) and oestrogen therapy. Br J Dermatol. 1986;115:269-74.

131. Mortimer PS, Dawber RPR, Gales MA, Moore RA. A doubleblind controlled cross-over trial of cyproterone acetate in females with hidradenitis suppurativa. $\mathrm{Br} \quad \mathrm{J}$ Dermatol. 1986;115:263-8.

132. Scheinfeld N. Treatment of hidradenitis supprurativa associated pain with nonsteroidal anti-inflammatory drugs, acetaminophen, celecoxib, gabapentin, pegabalin, duloxetine, and venlafaxine. Dermatol Online J. 2013;19:20616.

133. Horváth B, Janse IC, Sibbald GR. Pain management in patients with hidradenitis suppurativa. J Am Acad Dermatol. 2015;73:S47-51.

134. Schrader AMR, Deckers IE, van der Zee HH, Boer J, Prens EP. Hidradenitis suppurativa: a retrospective study of 846 Dutch patients to identify factors associated with disease severity. J Am Acad Dermatol. 2014;71:460-7.

135. Sartorius K, Emtestam L, Jemec GBE, Lapins J. Objective scoring of hidradenitis suppurativa reflecting the role of tobacco smoking and obesity. Br J Dermatol. 2009;161:831-9.

136. Bettoli V, Naldi L, Cazzaniga S, Zauli S, Atzori L, Borghi A, et al. Overweight, diabetes and disease duration influence clinical severity in Hidradenitis Suppurativa-Acne Inversa. Evidence from the national Italian Registry. Br J Dermatol. 2015. doi:10.1111/bjd.13864 (Epub ahead of print).

137. Vazquez BG, Alikhan A, Weaver AL, Wetter DA, Davis MD. Incidence of hidradenitis suppurativa and associated factors: a population-based study of Olmsted County, Minnesota. J Invest Dermatol. 2013;133:97-103.

138. Thomas CL, Gordon KD, Mortimer PS. Rapid resolution of hidradenitis suppurativa after bariatric surgical intervention. Clin Exp Dermatol. 2014;39:315-8.

139. Boer J. Resolution of hidradenitis suppurativa after weight loss by dietary measures, especially on frictional locations. J Eur Acad Dermatol Venereol. 2015. doi:10.1111/jdv.13059 (Epub ahead of print).

140. Kromann C, Ibler KS, Kristiansen V, Jemec GB. The Influence of body weight on the prevalence and severity of hidradenitis suppurativa. Acta Derm Venereol. 2014;94:553-7.

141. Miller IM, Ellervik C, Vinding GR, Zarchi K, Ibler KS, Knudsen KM, et al. Association of metabolic syndrome and hidradenitis suppurativa. JAMA Dermatol. 2014;150:1273-80.

142. Matusiak Ł, Bieniek A, Szepietowski JC. Hidradenitis suppurativa and associated factors: still unsolved problems. J Am Acad Dermatol. 2009;61:362-5.

143. Gaspari AA, Tyring S. New and emerging biologic therapies for moderate-to-severe plaque psoriasis: mechanistic rationales and recent clinical data for IL-17 and IL-23 inhibitors. Dermatol Ther. 2015;28:179-93.

144. Chiricozzi A, Krueger JG. IL-17 targeted therapies for psoriasis. Expert Opin Investig Drugs. 2013;22:993-1005.

145. Deeks ED. Apremilast: a review in psoriasis and psoriatic arthritis. Drugs. 2015;75:1393-403. 